\title{
Relevâncias da Experiência e Critérios de Potabilidade: conflito de interpretações sobre a água "boa" em uma localidade do Cariri
}

Carla C. Teixeira, Luís Cláudio Moura e Anna Davison

\section{(2) OpenEdition Journals}

Edição electrónica

URL: http://journals.openedition.org/aa/1092

DOI: 10.4000/aa.1092

ISSN: 2357-738X

Editora

Programa de Pós-Graduação em Antropologia Social (UnB)

Edição impressa

Data de publição: 1 dezembro 2011

Paginação: 55-81

ISSN: 0102-4302

Refêrencia eletrónica

Carla C. Teixeira, Luís Cláudio Moura e Anna Davison, «Relevâncias da Experiência e Critérios de Potabilidade: conflito de interpretações sobre a água "boa" em uma localidade do Cariri», Anuário Antropológico [Online], v.36 n. 1 | 2011, posto online no dia 20 novembro 2015, consultado o 28 abril 2021. URL: http://journals.openedition.org/aa/1092 ; DOI: https://doi.org/10.4000/aa.1092

\section{(c) (i) (9)}

Anuário Antropológico is licensed under a Creative Commons Atribuição-Uso Não-Comercial-Proibição de realização de Obras Derivadas 4.0 International. 


\title{
Relevâncias da Experiência e Critérios de Potabilidade: conflito de interpretações sobre a água "boa" em uma localidade do Cariri
}

\author{
Carla C. Teixeira \\ Universidade de Brasília \\ Luís Cláudio Moura \\ Doutorando do Departamento de História, UnB \\ Anna Davison \\ PPGAS, UnB
}

[A nossa terra]

Tem um açude, uma beleza

A água limpa e peixes mil

Com suas ilhas maravilhosas

Recanto verde deste país. ${ }^{1}$

\section{Introdução}

Granjeiro é uma pequena cidade de aproximadamente 5 mil habitantes, localizada na região do Cariri, o "oásis do sertão", situado no semiárido ao sul do Ceará. A região é extremamente rica em arte popular, sendo um conhecido polo de cultura no estado. O Cariri passou a ser regularmente povoado em 1703, ainda que se tenham notícias de incursões à região em meados de 1600, quando o governador geral de Pernambuco se encarregou de anexá-lo à sua capitania. As principais cidades da região são Crato e Juazeiro do Norte, que exercem grande influência sobre os municípios vizinhos. Juazeiro do Norte movimenta a região por ser uma das cidades mais relevantes no cenário do catolicismo popular brasileiro, já que ali viveu o padre Cícero, ${ }^{2}$ o que levou a cidade a se tornar um centro de peregrinações. Os demais povoados da região surgiram, em sua maioria, de missões de frades capuchinhos que se instalaram ali a fim de catequizar os índios Cariri que habitavam o local.

Conta o "mito fundador" de Granjeiro, porém, que o município não é fruto de uma missão religiosa, mas de uma história de amor fracassada. Segundo essa narrativa, Francisco David Pereira Grangeiro (apontado por muitos granjeirenses 
como seu bisavô) teria saído de Barbalha (cidade próxima) em finais do século XVIII em busca de um lugar onde pudesse se fixar e desposar uma moça pobre a quem sua família não aceitara, tendo encontrado no vale onde Granjeiro se situa as condições favoráveis para seu estabelecimento. Ali, ele e os poucos homens que o seguiam ergueram as primeiras construções para se abrigar. Tempos depois, quando já havia se estabelecido, Francisco voltou à Barbalha para buscar a moça e soube que ela já havia se casado com outro. Desiludido, aceitou casar-se com uma prima, com quem os pais gostariam que ele contraísse matrimônio. Após o casamento, Francisco retornou a Granjeiro acompanhado de mais algumas famílias e iniciou o povoamento da localidade que viria a se chamar Sítio Junco, devido à abundância dessa planta na região. O "pai” de Granjeiro teve vários filhos e sua genealogia se fazia presente na memória dos granjeirenses ainda em 2005, quando a pesquisa foi realizada, posto que grande parte da população tinha esse sobrenome, sendo esta, aliás, a razão para a atual denominação do município (ainda que a grafia do nome seja ligeiramente diferente).

A referência ao nome inicial do povoamento permanece na denominação do principal açude do município: o Açude do Junco. A construção deste açude remonta ao período entre 1932 e 1952, tendo modificado a relação dos habitantes da localidade com a água e com a cidade como um todo. ${ }^{3}$ Hoje é às suas margens que se encontra a atual sede do município de Granjeiro, ${ }^{4}$ constituindo-se em ponto central na vida do local, atraindo turistas (mesmo que a cidade não tenha estrutura - como hotéis e restaurantes - para recebê-los) e permitindo a plantação de culturas de baixio e a pesca.

Na breve semana em que foi realizada a pesquisa exploratória em 2004, já foi possível perceber a grande importância do Açude do Junco na localidade. Só no primeiro dia, houve três diferentes convites para visitar este açude. As pessoas, nessas ocasiões, seguiam um roteiro parecido, mostravam a Avenida Central (uma espécie de calçadão às margens do Açude, que era assim denominada e que na época ainda estava em construção) como a menina dos olhos da cidade, toda a sua beleza ali concentrada. Essas pessoas chamavam por vezes o Açude e a Avenida de balneário, a praia no meio do sertão. O principal bar da cidade também ficava em suas margens e os grandes acontecimentos da cidade, como o carnaval, as comemorações políticas e as festividades públicas, aconteciam ali. Há cerca de 10 anos suas águas passaram a ser tratadas e encanadas para a sede do município e o Açude consolidou-se, de fato, como o maior motivo de orgulho da população granjeirence (Figura 1). 


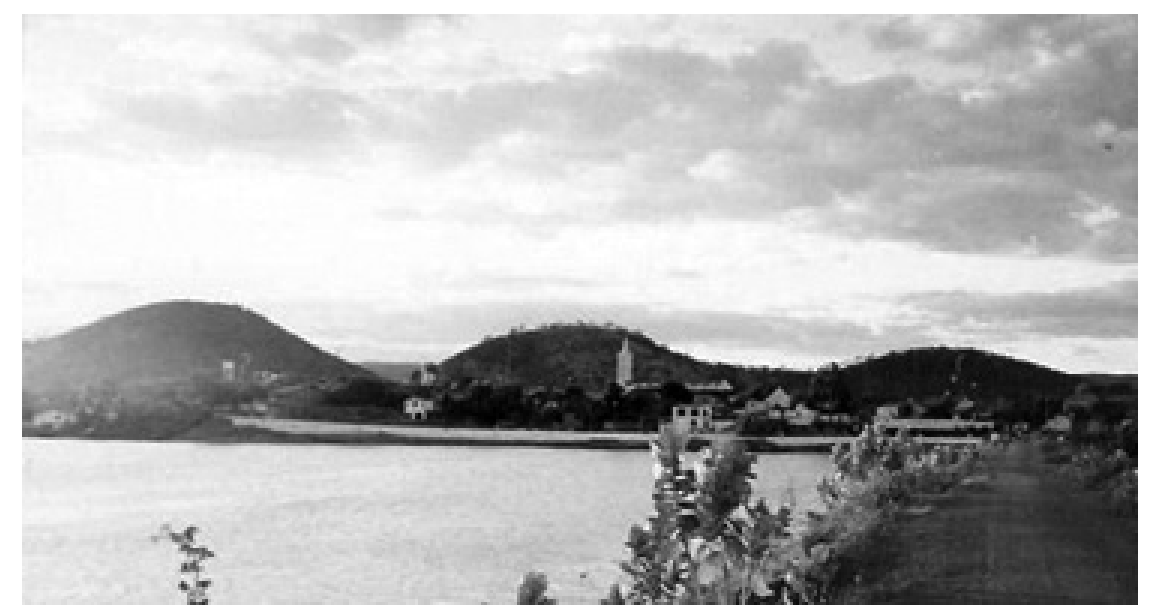

Figura 1: Açude do Junco

Entretanto, a relação entre os granjeirences e seu açude é ambígua: de orgulho pela alegria, o lazer e a renda que ele proporciona, mas também de desconfiança e receio pelas mortes que nele já ocorreram e pelos usos considerados indevidos que dele alguns faziam. Essa relação levou a um singular imbricamento entre o Açude e o cotidiano dos habitantes de Granjeiro, cuja relevância pôde ser percebida já nos primeiros dias de convivência na cidade. Qual não foi a surpresa quando se constatou que a água do Açude tratada pela Companhia de Água e Esgoto do Ceará (CAGECE), e conduzida por encanamentos até as residências, era usada para várias atividades, predominantemente para aquelas que não envolvessem ingestão humana, ou seja, não era bebida nem utilizada para cozinhar. Para tais finalidades os granjeirences utilizavam a água dos vários "chafarizes" - conjuntos de bicas construídos pela prefeitura em diferentes pontos da sede do município - que tinha que ser carregada em recipientes até os locais de moradia. Se num primeiro momento a racionalidade econômica parecia se impor como explicação para tal preferência - afinal a água dos chafarizes, embora exigisse um dispêndio de energia física e de tempo, era gratuita - o dia a dia na localidade revelou uma tessitura muito mais densa de significados, valores e interações sociais em torno das águas de Granjeiro. Compreender esta densidade e as distintas lógicas e percepções que a perpassam, tomando como fio condutor a rejeição à água tecnicamente potável, ${ }^{5}$ foi justamente o desafio que orientou a pesquisa e ensejou a escrita deste artigo. ${ }^{6}$

\section{A pluralidade e a hierarquia das águas}

As diferentes fontes de água de Granjeiro se dividiam principalmente em água dos açudes, do chafariz, de poços e cacimbas e água armazenada da chuva. 
Contudo, estas diferentes águas não têm o mesmo valor, sendo que é em relação às águas do Açude do Junco que as demais águas na sede do município, nosso foco aqui, são classificadas. Em meio a esta diversidade, algumas águas se destacavam, formando um triângulo denominado pelos granjeirences com os seguintes termos: água do açude, água do chafariz e água da chuva - a oposição entre açude e chafariz apresentando-se como a dominante. Cada uma delas era, por sua vez, possuidora de virtudes e perigos que compunham uma paisagem cultural na qual a experiência sensória dominava, mas não excluía a consideração das qualidades de potabilidade da água. No entanto, antes de discutirmos como a percepção sensória, a interpretação cognitiva e a atribuição de significados se enredavam em Granjeiro, é preciso conhecer mais de perto essas águas.

\section{A água do Açude}

A água potável encanada a partir do Açude do Junco, como vimos, é algo recente, tem em torno de 10 anos para a sede e de um ou dois anos para alguns sítios próximos. Esta função do açude foi aceita diferentemente entre as comunidades da sede e as dos povoados que a receberam, estando relacionada com a disponibilidade de outras fontes de água, bem como com a apreensão que se fazia de sua ocupação humana, como veremos a seguir.

Em termos econômicos, as áreas mais próximas às margens do Junco eram utilizadas para o plantio de arroz, feijão, bananas, favas, milho, entre outros. Muitas famílias tiravam sua renda, ou parte dela, destas terras. A prática da pesca em suas águas fornece outra fonte de alimentos e de renda para os moradores de Granjeiro. Alguns habitantes da sede eram pescadores que, além de pescarem para o consumo próprio e o da família, promoviam o comércio de peixe em Granjeiro. No centro da cidade encontramos "banquinhas" a oferecer o pescado local na principal rua comercial. O peixe também ajudava a mover a economia granjeirense como o principal e o mais pedido "tira-gosto" dos bares localizados na Avenida, o principal local de diversão e atração turística. A atividade do turismo, embora restrita à visita ao açude nos finais de semana, ${ }^{7}$ foi reforçada com a urbanização de parte das margens do Junco (Figura 2).

O elogio de sua existência para o bem viver em Granjeiro convivia com usos não tão nobres de suas águas, embora importantes para uma parcela de seus moradores. Assim, em volta do Açude podiam ser avistados alguns poucos currais e chiqueiros de porcos em suas margens mais remotas, sendo corriqueiro, porém, encontrar animais passeando à beira do açude, tomando água ou defecando, ou mulas e cavalos sendo banhados por seus donos. Muitas outras coisas eram também lavadas em suas águas: bicicletas, louças, tripas de porco ("fato de porco") e, principalmente, roupas - tanto como prática doméstica quanto como ocupação econômica (das chamadas "lavadeiras"). 


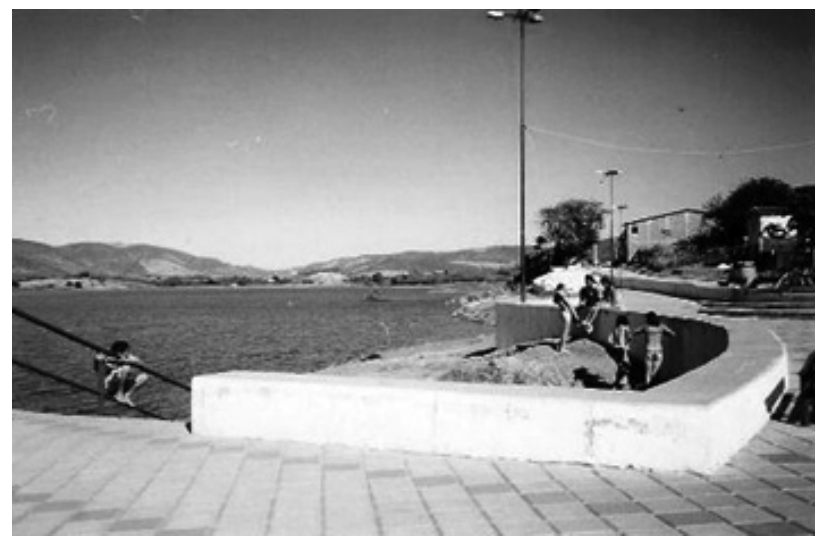

Figura 2: Margens do Açude do Junco

A marca deste grande açude na paisagem local, contudo, não se esgotava em seu domínio do horizonte espacial nem das interações cotidianas, seja pelo lazer proporcionado, seja em sua importância econômica. O Junco também inspirou um repertório de "mitos" lhe eram atribuídas características humanas. Em geral, as características eram negativas, quase sempre relacionadas com a morte, mais precisamente com afogamentos, narrados por muitos como "assassinatos" cometidos pelas águas "traiçoeiras" do Junco. Contavam-se casos de incidentes no Açude nos quais apareciam frases como: "este açude é assassino", "açude criminoso" e "quando o açude geme, alguém vai morrer”.

Tantas dimensões, como já se pode vislumbrar, viriam a compor o enquadramento dado pelos moradores à água tratada do Açude e, consequentemente, às demais águas de Granjeiro, como abordaremos mais adiante.

\section{A água do Chafariz}

A água do chafariz era distribuída em quatro pontos espalhados pela sede municipal. Os pontos de água foram construídos de forma padrão: três ou quatro torneiras, da altura de meio metro, localizadas dentro de "casinhas" de alvenaria, quase todas sem porta. Os chafarizes existentes na cidade, contudo, apresentavam diferentes estados de manutenção e a proteção dada às fontes não era suficiente para mantê-las livres dos animais (Figuras 3 e 4). Era comum ver cachorros, gatos e aves, que passeavam livremente pela cidade, tomando a água que escorria abaixo das torneiras, às vezes chegando mesmo a entrar nas casinhas para melhor se servirem. 


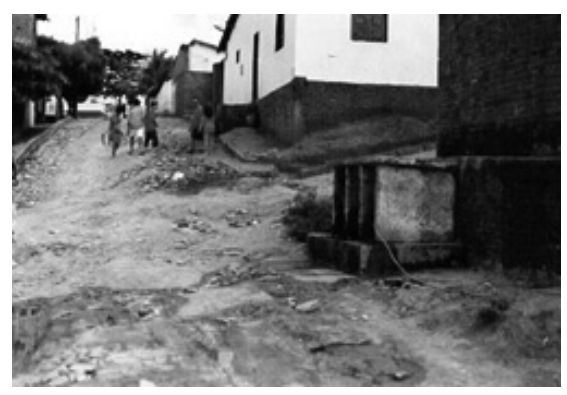

Figura 3:

Chafariz na periferia da sede do município

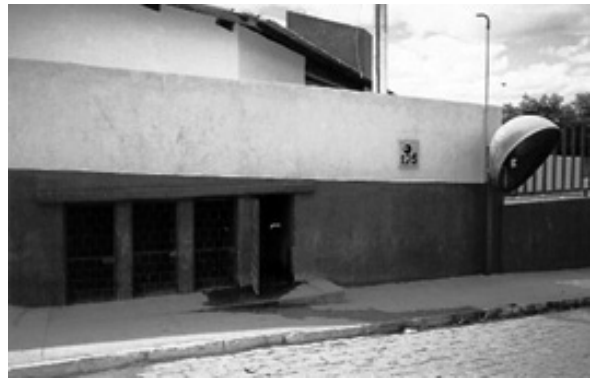

Figura 4:

Chafariz no centro da sede do município

Esta água não era paga, como foi dito anteriormente, pois vinha de um poço de responsabilidade da prefeitura e, segundo as autoridades locais, quando em meados dos anos 90 foi implantado o sistema de água da CAGECE, o poço da prefeitura foi fechado: "eles colocaram lá uma setazinha dizendo que estava encerrado o atendimento através daquele poço, que seria da indústria de água que tem no município, da CAGECE". ${ }^{9}$ Posteriormente, o poço teria sido reaberto, reformado, sua água passando a ser distribuída para os chafarizes sob o alegado argumento do prefeito, conhecido como Dr. Soares - o mais popular da localidade - de que nem todos poderiam pagar pela água encanada ${ }^{10}$ e, portanto, deveriam ter acesso gratuito a ela sem precisarem se deslocar para o poço situado fora do núcleo urbano.

Assim, a água era coletada nas bicas em baldes ou latas e transportada até as casas, havendo à época alguns rapazes que cobravam para fazer este transporte. ${ }^{11}$ O maior movimento nestas fontes ocorria pela manhã, entre 6 e 8 horas. Nestas primeiras horas do dia, as bicas começavam a receber a visita dos moradores. Não era raro verem-se filas de baldes ou outros recipientes diversos na frente das bicas, sendo estes frequentemente lá esquecidos transbordando, enquanto as pessoas (homens, mulheres e crianças) se envolviam em outros afazeres. Apesar do fluxo se concentrar neste horário, a fonte recebia a visita de moradores durante todo o dia, pois esta era a água preferida para beber, cozinhar e banhar-se, enfim, para a maioria das atividades em que os sentidos do corpo eram acionados.

\section{A água da chuva}

Armazenar água de chuva era um costume existente em Granjeiro e em várias outras cidades nordestinas. Sendo inicialmente feito de maneira improvisada, a coleta da chuva, a partir dos anos 2000, passou a fazer parte das estratégias governamentais de combate à falta de água. Em alguns sítios foram encontrados 
sistemas construídos pelo poder público local para amenizar a seca, em especial, naqueles fora da sede do município, onde não havia água encanada e cuja localização dificultava obter água através da escavação de poços. Estes sistemas consistiam na captação e no armazenamento da água da chuva em reservatórios abastecidos pela água que cai sobre o telhado. Na ocasião da pesquisa, seis meses após a estação chuvosa, tivemos acesso a uma caixa de captação, ${ }^{12}$ onde havia em torno de 20\% da capacidade do reservatório.

Se esta solução era a mais recente a ser utilizada pelo município para a obtenção de água, pudemos constatar, no entanto, que este tipo de captação era tradicionalmente feito pela população, independente da disponibilidade de outras águas. Em uma das visitas à casa de dona Léa, ${ }^{13}$ uma das principais interlocutoras da pesquisa, observou-se que a senhora também armazenava água da chuva, mas o armazenamento era feito através das calhas do telhado e colocado em um recipiente de uns 100 litros de capacidade. Como era o costume, não armazenava a água da primeira chuva, pois, segundo dona Léa, como esta água era "suja", sua destinação era apenas para lavar roupa. O uso da água das demais chuvas era mais diversificado e, como se ouviu diversas vezes, a água da chuva era considerada especialmente boa para lavar os cabelos (deixava-os "mais macios”). Contudo, sua relevância, até por sua intermitência, era menor em relação às águas do Junco e dos chafarizes, exercendo uma função claramente complementar nesta triangulação.

\section{A contraposição central: as águas do Açude e do Chafariz}

Como se observou, existia uma diversidade de águas em Granjeiro, entretanto, todas "estas águas" não estavam presentes ao mesmo tempo e na mesma comunidade (sede do município e sítios). Sua composição e sua utilização variavam conforme a localidade e a oferta dentro do município, e também de acordo com a estação climática, dividindo-se em verão (seca) e inverno (chuvas). As estações produziam diferenças significativas quanto aos usos da água devido às limitações impostas pela ausência e pela alteração da qualidade da água provocada pela estiagem.

Estas características, aliadas às avaliações feitas pelos moradores, nos levaram a traçar diferentes usos das águas cruzando o espaço e o tempo para observar como isto acontecia. Tais diferenças apresentam-se ou sobressaem-se em face das demais atividades quando consideradas em relação à água utilizada para beber. De início, há que compreender a polarização de atitudes diante das duas águas principais do município de Granjeiro: a qualificação como boa da água gratuita dos chafarizes em detrimento da água paga do açude, apontada como 
inferior. Na evitação em fazer uso da água do açude para consumo humano, frequentemente nos deparamos com explicações em que não havia a elaboração de motivos de ordem "físico-química" para a sua rejeição, já que a purificação através do tratamento era afirmada em seus discursos. Em geral, as pessoas reconheciam que o tratamento da CAGECE era efetivo e que a água poderia ser ingerida. Entretanto, nos labores cotidianos não o faziam e, apesar de respaldarem a qualidade do tratamento, se insistíssemos nas indagações, davam a entender que a água não estava, de fato, adequada a todos os tipos de consumo.

Tal inadequação era apreendida pelas diferentes dimensões da experiência com a água do Açude, apontadas anteriormente. Dentre os motivos declarados para não bebê-la, destacava-se a crítica às lavadeiras que frequentavam diariamente o Junco (Figura 5).

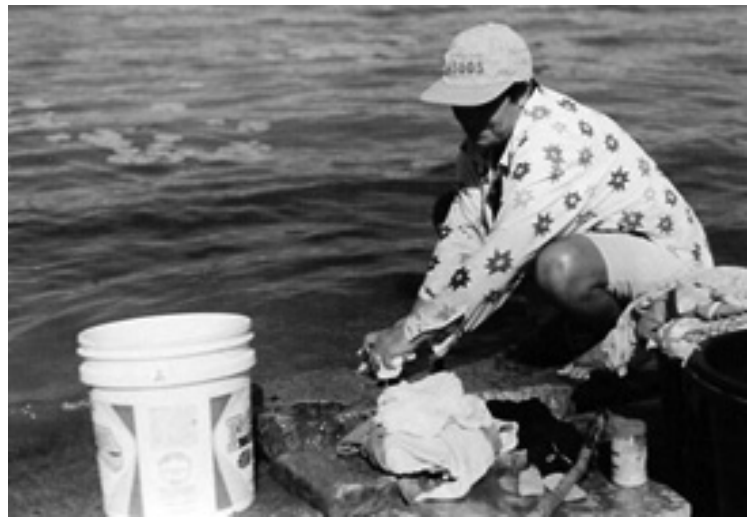

Figura 5: Lavadeira à beira do Açude do Junco

De fato, lavar a roupa fora de casa era uma prática comum em todo o município e aqui a alegação econômica se explicitava: lavar roupa em casa com água encanada aumentaria excessivamente o valor da conta a ser paga à CAGECE principalmente para as mulheres que lavavam roupa para terceiros. ${ }^{14}$ Contudo, o hábito de deixar mangueiras abertas para "aguar" as plantas do quintal nos alertou para os limites deste argumento e para a necessidade de uma escuta mais qualificada das narrativas sobre a hierarquia das águas granjeirences. Foi assim que se pôde apreender em conversas com moradores que, exceto em relação à lavagem das roupas, a restrição quanto ao preço da água encanada não aparecia como um dos primeiros motivos declarados para restringir seu uso.

As qualidades sensórias distintivas das águas - sabor, cor e pureza visual, tátil ${ }^{15}$ - eram as alegações para a preferência pela água do chafariz: "A senhora apanha água no chafariz para beber. Disse que a água é boa, que tem um gosto bom e que as pessoas de fora falam que a água tem um gostinho doce" (notas de 
campo). Já em relação à água do Açude, uma estudante, cujo trabalho sobre a importância da água em Granjeiro havia sido premiado na feira de ciências da escola, nos contou que para ela o açude era poluído, sendo esta poluição proveniente do lixo jogado às margens do reservatório nos fins de semana e cujo aumento se fez sentir depois da construção da Avenida. Dentre outros aspectos repulsivos, havia também a já mencionada presença de animais em suas margens, o banho no açude e as mortes em suas águas.

Se tal classificação das águas não era característica de um tipo de pertença social em Granjeiro, aqueles em posições de autoridade, quando entrevistados, explicitamente a desconsideravam como produto da ignorância. Nas palavras do então prefeito:

É, aqui é assim, [para] o pessoal ainda falta um pouco de consciência do entendimento de que água tratada, água potável tratada, ela acaba [com] todos os riscos de doença. Mas as pessoas por influência acham que a água que está com 60 metros [do poço que supria os chafarizes], sem ela passar pelo processo de tratamento, ela fica melhor que a do açude sendo tratada, e que eu mesmo bebo água do açude, eu tomo água do açude todo dia, e eu acho que a água do açude é muito boa (Entrevista em 29/07/2005).

Cabe considerar, primeiro, a contradição de informações sobre a existência ou não de tratamento da água distribuída nos chafarizes entre os responsáveis políticos. Se nesta ocasião o prefeito sugeriu não haver tratamento da água do chafariz, em outra oportunidade o vice-prefeito afirmou serem ambas as águas sujeitas aos mesmos procedimentos de tratamento. ${ }^{16} \mathrm{O}$ mais importante, entretanto, é observar que não se trata principalmente de uma lacuna nas informações sobre a eficácia dos procedimentos técnicos de purificação da água do Açude (quanto aos "riscos de doença”), mas de outros registros de apreensão que não parecem passíveis de alteração por meio de tais procedimentos.

Assim, a apreensão visual parecia constituir uma diferença significativa entre a água do açude e a do chafariz, em sentidos que não se esgotavam naqueles propiciados pela visualização dos usos considerados poluidores do açude. Se a água do açude chegava pelo encanamento da CAGECE até as casas, sendo, portanto, de responsabilidade desta companhia, no interior de cada residência os cuidados de infraestrutura e armazenamento tornavam-se atribuição de cada morador. A água que saía do açude, em geral, era armazenada nas caixas de água, onde nem sempre as condições de limpeza eram as adequadas. A água que saía do encanamento era turva, indicando que as condições da caixa d'água e do encanamento 
interferiam na sua qualidade. Na casa em que moramos foi necessário quebrar a parede para desentupir um cano que estava bloqueado devido, segundo o senhor que reparava o problema, ao acúmulo de barro e de lodo na caixa d'água. ${ }^{17} \mathrm{No}$ entanto, em diversos momentos, as pessoas declararam que lavavam constantemente o reservatório, ${ }^{18}$ mas que este voltava a ficar sujo muito rapidamente, em uma valoração que parecia atribuir à água do açude qualidades impuras mais severas do que as encontradas em outras águas.

A água proveniente do chafariz, por sua vez, apesar de seu transporte em baldes e latões, era visivelmente mais transparente que a do açude. Do chafariz, a água era imediatamente armazenada em um jarro, sendo por vezes coada em um pano, como era comum ser feito também com as demais águas, onde, com o passar do tempo, qualquer sujeira seria decantada. ${ }^{19}$ Esta prática, deixar a água dormir, descansar de um dia para o outro, foi indicada também para a água do açude, mas com objetivo diferente. Segundo seus moradores, com o descanso do líquido, o gosto de cloro diminuía, pois ficava assentado no fundo do recipiente. Deixar a água do açude armazenada alguns dias era, assim, a solução dada por diferentes camadas sociais para o problema do gosto do cloro:

É o seguinte: eu tenho, por exemplo, três tambores, que eu encho lá em casa hoje, então, hoje é que dia? Terça. Só lá para sexta-feira [é] que eu começo a utilizar, entendeu? Ela dorme esses dias todinhos por questão da... eles botam cloro, essa coisa toda, então, se usar ainda hoje, ela fica muito com um gosto diferente, né? Então, quando é lá para quinta, sexta-feira, que ela tem dormido, adormecida, fica uma beleza (secretário de gabinete de Planejamento e Coordenação; entrevista em 19/07/2005).

Desta perspectiva, os sentidos do paladar e da visão prevaleceram, completando-se e confirmando-se mutuamente: a água do chafariz era indicada como boa porque não tinha gosto - ou quando o tinha, era apreciado - e por ser transparente e pura; por sua vez, a do açude possuía um forte gosto, rejeitado pela população, atribuído principalmente ao tratamento do cloro e ainda à sua turbidez e sujeira. Assim, observamos que cozinhar com a água do chafariz era uma opção generalizada na sede de Granjeiro. Os motivos para esta escolha nos foram explicados e, também, foram fáceis de serem verificados em campo. A água do açude, ao ferver, produzia dois fenômenos: a panela ia ficando negra onde a água entrava em contato com o metal e produzia uma "nata" bege sobre a sua superfície (Figura 6). 


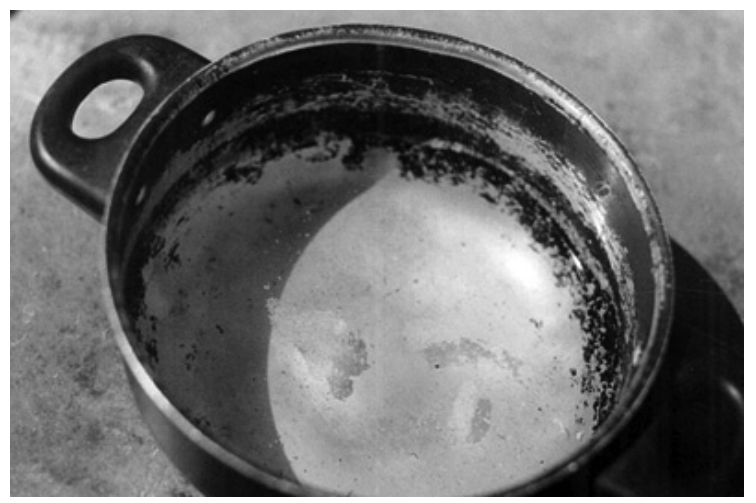

Figura 6: "Nata" na água após fervida e aspecto da panela

Diante de tais fenômenos, a variação dos usos da água não se dava apenas para a ingestão humana. As diferenças revelaram-se perceptíveis o suficiente para contribuir para a destinação diversa das duas fontes para outras atividades também. Assim, encontramos relatos sobre os efeitos produzidos no corpo. Para alguns granjeirences, as águas traziam reações distintas na pele e nos cabelos: a água encanada do açude ressecava-os, provocando inclusive coceira na pele, ao contrário da água do chafariz; e no interior do corpo causava dores de estômago, de intestino e problemas no fígado em função do excesso de cloro que continha.

Para diversas pessoas consultadas durante o trabalho de campo, existia ainda mais um motivo para recusar a água do açude: sua poluição pela morte. Chamou-nos a atenção, contudo, o fato de que tal poluição não se daria apenas pela ocorrência de mortes em suas águas, mas também pela presença de objetos de pessoas falecidas e pela água da chuva que escorria do cemitério para lá. ${ }^{20}$

Em geral, as pessoas que relataram ser comum o Junco receber pertences de pessoas mortas percebiam esta prática como algo corriqueiro. Em certa ocasião, uma senhora qualificou suas águas como sebosas, porque roupas de mortos foram retiradas dali. De fato, o açude parece ter sido usado, por vezes, como depósito de lixo em geral. Soubemos que pouco antes de chegarmos à cidade havia sido feita uma limpeza no Açude, tendo sido removidos vários objetos; e durante o período de pesquisa na cidade vimos garrafas - de vidro e de plástico - e sacos plásticos em suas águas. No entanto, não tivemos como avaliar se jogar roupas e outros pertences de mortos no açude era uma prática de fato comum, como foi sugerido em algumas falas, importando que isto era realmente considerado por muitos.

Para reforçar as qualidades das águas do chafariz resta, por fim, destacar que elas eram consideradas livres desses tipos de contaminação pelo fato de serem oriundas, segundo reza o conhecimento local, de um poço cuja profundidade 
seria de 25 metros para alguns e de 60 metros para outros. Tal profundidade original explicaria sua qualidade (gosto e transparência), pois os contatos com humanos (por imersão de vivos e mortos) e com animais eram tidos, junto com o cloro, como o principal componente poluidor das águas de Granjeiro. Neste caso, com a fonte do chafariz a dezenas de metros terra adentro, suas águas estariam fora do alcance de tais poluentes.

Se considerarmos, contudo, que as ações de abastecimento de água que levaram ao tratamento das águas do Junco e à sua distribuição para as residências faziam parte de uma política do Ministério da Saúde (o Projeto Alvorada, do então ministro José Serra), que visava diminuir a incidência de doenças através de veiculação hídrica em municípios com índice de desenvolvimento humano muito baixo (menor do que 0,5), é importante abordar as consequências dessa hierarquização das águas e a pluralidade de seus usos segundo a racionalidade sanitária, bem como o modo com que as autoridades locais agiam diante deste cenário.

\section{Prestígio das águas, discursos e práticas}

Durante a pesquisa de campo, a questão da oferta de água se fez presente de maneira fluente e espontânea nos discursos de nossos interlocutores. $\mathrm{O}$ assunto fazia parte da ordem do dia em Granjeiro. Falava-se com muita desenvoltura e conhecimento de causa sobre seca, saneamento e água. O tema era pauta na escola, nas conversas na Avenida (sendo esta também motivo de assunto) e nas ações instrutivas realizadas pela prefeitura e pela CAGECE.

De fato, encontramos um ambiente propício para conversas sobre água e saneamento. As obras públicas realizadas nos últimos anos haviam sido diversas (água, rede de esgoto e melhoria sanitária domiciliar ${ }^{21}$ ) e as ações "educativas"22 foram implantadas em vários momentos. Todos pareciam ter algo a dizer, individual e coletivamente, fornecendo pistas para desvendar as relações dos granjeirences com a água e buscar uma melhor compreensão do que diziam e como diziam. Os discursos eram muito parecidos, contribuindo para que seus conteúdos e formas alcançassem certo estatuto de verdade. ${ }^{23}$ Assim, ouvimos comentários sobre problemas de saneamento, práticas sobre coleta e armazenamento de água ou teorias sobre as distintas qualidades das fontes, tendo como referencial a diferença entre o tempo anterior e o posterior à chegada da água potável e do saneamento, ocorrida na maior parte do município. Discutimos com adolescentes, adultos, pessoas mais idosas, homens e mulheres, trabalhadores das mais diversas profissões, representantes da sociedade civil e membros do poder público. Colhemos opiniões, a partir de um amplo horizonte de perspectivas, dentro da comunidade de Granjeiro. 
O processo ao qual creditamos a promoção deste ambiente de aparente consenso em torno das águas foi um programa exigido pelo Projeto Alvorada. ${ }^{24}$ Tratava-se do Programa de Educação em Saúde e Mobilização Social (PESMS), concebido como parte da contrapartida estadual para a efetivação das obras de saneamento empreendidas por este Projeto. ${ }^{25}$ A CAGECE ficou responsável, então, pela execução desta atividade no estado, englobando ao todo 10 municípios, sendo constituída por palestras e encontros com o apoio do município e das associações de moradores, realizados em período reduzido e focando não só no desperdício de água, mas também em sua qualidade. Em articulação com esses eventos, também foram utilizados folders e cartazes para a divulgação das ideias pretendidas. ${ }^{26}$ Talvez uma das estratégias mais criativas tenha sido um pequeno esquete ("A velha surda") representado por um casal de adolescentes, que abordava o tema da água e no qual havia falas como: "a água é muito importante", "a água de nossa cidade é muito boa”, "a água é patrimônio nosso" e "não lavo nem calçada pra não gastar a água”.

Esta última fala expressava a opinião generalizada e predominante quanto à necessidade de evitar o desperdício ou, de acordo com a expressão local, de não "istruir" a água. Esta questão era defendida pelos granjeirences (comunidades e gestores públicos) e propagada por eles. Em todas as entrevistas realizadas e nos grupos de discussão, ouvimos a respeito da importância de economizar a água e do seu papel fundamental no mundo. Nas palavras do então prefeito:

Existe esse problema que é no mundo todo, o desperdício. Que é uma preocupação minha em fazer esse controle ainda. Eu acho que aqui há um desperdício de 10 a 15 por cento da água potável, aqui ainda. E eu não admito e nem eu posso admitir, porque a escassez de água está no mundo todo, vai acontecer já, já, talvez, assim, um princípio de colapso, e aqui nós temos um pouco de água e eu quero conservar esse pouco de água que existe no planeta.

[E]u acho que a comunidade tem que se conscientizar de que realmente isso é um bem muito precioso e não deveria desperdiçar. E nas localidades existem os projetos; o governo tem que nos ajudar a favorecer essa interligação entre o governo federal, o estadual e o município, para que nós possamos colocar a água à disposição desse povo (Entrevista em 29/07/2005). 
Apesar de sabermos que existiam outros pontos de discussão nas atividades chamadas educativas ou de conscientização, o que era destacado nas falas de autoridades e moradores era o não desperdício da água. As falas faziam referência a questões tanto mundiais como locais, com espaço para a demonstração de uma consciência sobre a importância da água no mundo e de sua valorizada agenda. Era comum os granjeirenses, após terem comentado a situação de escassez do produto no planeta, voltarem-se para a questão no município, indicando a falta da água na localidade e seu significado fundamental para a manutenção da qualidade de vida naquela região.

Se no registro discursivo o foco parecia estar bem estabelecido, verificamos com o passar do tempo que este foco se fazia mais presente nos ditos do que nos feitos, a começar pelas próprias ações governamentais.

Assim, o carnaval de 2004 - o primeiro na recém-construída Avenida - teve como cena emblemática: o prefeito a molhar os foliões com uma mangueira, enquanto as pessoas dançavam e se divertiam por horas. Já em 2005, o Concurso Garota Molhada era o evento mais esperado e constantemente comentado. O concurso não era Miss Granjeiro, ou Rainha da Vaquejada, ${ }^{27}$ ou da Avenida, mas sim Garota Molhada, mais uma vez trazendo a força da água na vida do município. O concurso tinha o seguinte roteiro: as meninas deveriam estar molhadas na hora do desfile para serem avaliadas pela população e pelos jurados (em geral, políticos locais). Diferente do que costuma ocorrer em competições entre fisiculturistas ou nos concursos de beleza, as concorrentes não estariam untadas com óleos ou cremes; aqui a água era utilizada como agente potencializador da beleza dos corpos, tornando as curvas mais sinuosas, favorecendo que as roupas colassem no corpo e acentuando a sua transparência. ${ }^{28}$

Esses eventos nos fizeram refletir sobre a natureza contextual e a inserção social dos sujeitos na definição dos manejos e das moralidades da água em Granjeiro. Se no dia a dia os granjeirences eram unânimes em afirmar o valor da água e sua necessária economia, nesses eventos excepcionais era permitido e requerido que alguns exercessem usos mais generosos e não instrumentais da água, dando margem a reafirmações e reconfigurações de poder político e de prestígio social de indivíduos, grupos e do próprio município. $\mathrm{O}$ valor dado à água, como bem escasso em um ambiente onde existia uma memória profunda e recente de momentos de seca, parecia estar sendo redefinido em contextos lúdicos a partir de uma nova realidade de relativa oferta. Tal redefinição, contudo, implicava um processo diferenciador entre pessoas em posições sociais diversas ${ }^{29}$ que, em determinadas situações, podiam e deviam, com legitimidade ampliada, desconsiderar a máxima rotineira de não desperdiçar água. Assim, a Avenida às 
margens do Junco, o lugar que se fazia palco da vida pública, tornava-se a arena onde a simbologia da fartura da água sobrepujava à da carência, e o "deve ser" cotidiano da conduta econômica cedia espaço à atitude de abundância despreocupada.

Tal atitude também se fazia presente, mas de forma absolutamente distinta, nas atividades diárias. Se as práticas de limpeza de casas, calçadas e carros, de regadio de plantas e quintais eram realizadas a partir da lógica da fartura, com mangueiras abertas ou baldes de água, havia a compreensão daqueles que assim o faziam de que tais hábitos não eram moralmente aprovados. Diferente do que observamos nos eventos públicos na Avenida, havia certo zelo em ocultar tais práticas. Certa ocasião, em uma das visitas feitas à casa de Vânia, contrariando o que ocorria normalmente, ela não nos chamou para entrar em sua casa e ver seu quintal; o motivo alegado: a mangueira estava aberta continuamente para molhar as plantas. A mulher, que conhecia o tema de nossa pesquisa, nos disse de forma jocosa: "na frente de vocês não posso desperdiçar água". Esta não foi a primeira vez que presenciamos a mangueira ligada por longos períodos e sabíamos que as plantas eram molhadas quase diariamente desta forma por vários moradores.

Se na agenda política que demarcava a necessária economia de água a adesão local, em sua aparente homogeneização, apresentava nuanças entre atividades rotineiras e excepcionais, lúdicas e laborais, públicas e domésticas, a pauta de ações em saúde, que afinal orientou a implantação das melhorias no abastecimento de água em Granjeiro (via Projeto Alvorada e CAGECE), parecia estar ausente das preocupações de quase todos. A referência aos riscos de adoecer por meio das águas não era muito acionada, diferente de quando falavam sobre as ações de esgotamento sanitário recentemente implantado, e a avaliação dos riscos epidemiológicos do consumo das diferentes águas tampouco se fazia presente.

Do ponto de vista sanitário, a água a ser consumida deveria ser a que, oriunda do Junco, passava pelo tratamento da CAGECE e era distribuída para as residências. Contudo, como exaustivamente expressado em campo, esta água não era considerada de boa qualidade, continuando a água encanada a ser chamada de "água do açude". Tal denominação indicava que sua qualidade, na opinião dos moradores, não parecia ter sido muito alterada pelo tratamento da CAGECE e, quando tal transformação era apontada, fazia-se de forma negativa em função da presença do cloro, de sua impureza acentuada e da capacidade de tornar-se suja nas caixas d'água residenciais. Em relação à água dos chafarizes, além das dúvidas sobre se receberia ou não algum tratamento que a qualificasse para o consumo humano, observamos a vulnerabilidade das bicas e também o fato de que no transporte a água entrava em contato com recipientes e mãos que 
não haviam passado pelos procedimentos de limpeza, conforme prescritos pelas orientações da vigilância em saúde - nem ao menos presentes na localidade. Nas casas, grande parte dos recipientes de água não tinha torneira na base, sendo a água retirada por meio de canecas ou outros utensílios que eram imersos na abertura superior do pote, em geral mantida coberta, e consumida sem que fosse fervida ou clorada.

Se tais práticas são consensualmente consideradas um risco epidemiológico e sanitário, ${ }^{30}$ isto não foi verificado nas falas dos moradores, das autoridades locais e nas mensagens das ações "educativas" da CAGECE. O meio de transporte e o armazenamento da água não eram vistos como elementos contaminadores importantes ou como pontos favoráveis à poluição da água, não havendo muita preocupação com o seu manuseio. Se o tratamento pelo qual a água do açude passara após ser de lá retirada não logrou modificar positivamente sua qualidade original, tampouco o manejo posterior da água extraída do poço da prefeitura e levada até os chafarizes parecia ter a capacidade de transformar negativamente sua pureza. Assim, esses procedimentos e a própria estrutura física dos chafarizes eram, se considerarmos as noções epidemiológicas, agravados pelo fato de os granjeirences (moradores em geral e autoridades locais e estaduais) não concebê-los como um risco a ser evitado.

Do ponto de vista da engenharia sanitária ou de saneamento, na opinião de vários engenheiros a quem os resultados da pesquisa foram apresentados, ${ }^{31}$ os moradores teriam razão em recusar a água da CAGECE pelo fato de o "manancial” (o Açude do Junco) de onde era captada não ser "protegido", ou seja, ser utilizado para lazer, ser de fácil acesso para os animais etc. A dificuldade surgia quando destacávamos que qualquer proteção ao açude ou, melhor, restrição ao seu uso, embora pudesse ser considerada apropriada do ponto de vista técnico, teria de levar em consideração sua centralidade na vida local, sob o risco de não se obterem os efeitos almejados. Aqui o convívio entre preceitos técnicos e dinâmicas sociais da água já anunciava impasses que pareciam irredutíveis.

Se havia o reconhecimento da razoabilidade da rejeição da água tratada do Açude do Junco, em função das condições de exposição em que o açude se encontrava, a recusa à cloração da água e as queixas expressas sobre os efeitos sentidos no seu consumo eram descartadas. O argumento da eficácia química do cloro na eliminação de organismos patogênicos, aliado à alegada relação custo-benefício desse processo, parecia impermeável à realidade local que apresentávamos. ${ }^{32}$ Diante da ponderação de que esta eficácia ficava totalmente anulada pela não ingestão da água clorada, a reflexão era que se deveria investir na mudança deste comportamento por meio de ações "educativas" ou de "conscientização", 
desconsiderando que a cloração era claramente reconhecida pelos moradores como uma ação que visava melhorar a água, mas não era experienciada desta forma por eles.

Afinal como podemos compreender tal conflito de interpretações sem desconsiderar as distintas posições e pretensões de verdade em disputa quanto às águas de Granjeiro?

\section{Sobre o que estamos falando: lógicas, visões ou experiências no mundo?}

Como descrito ao longo deste artigo, a investigação feita em Granjeiro nos permitiu esboçar um complexo de significados e práticas em traçados que se definiram a partir de percepções, relevâncias, relações, posições, valores, espaços e tempos orientadores da e orientados pela diversidade das águas. Tal complexo, por sua vez, nos revelou um desencontro entre ações de governo (federal, estadual e municipal) e mundo da vida dos granjeirences: de um lado, recursos públicos foram aplicados no tratamento de água e em sua distribuição até os locais de moradia, em ações "educativas" que orientassem a população quanto ao seu uso, sendo ao mesmo tempo disponibilizado um tipo de água que requeria que os moradores a transportassem até suas casas, gratuita, mas cuja potabilidade para consumo não parecia estar claramente estabelecida; por outro, os moradores se recusavam a beber, a cozinhar e a banhar-se com a água tratada, preferindo a água duvidosa tecnicamente, mas apreciada sensitivamente.

Numa mirada exotizante, tudo poderia indicar certa incomensurabilidade entre mundos: o mundo das águas definido positivamente em termos técnicos não conseguia se tornar compreensível ao mundo das águas constituído em termos sensoriais e pragmáticos. Tal incomensurabilidade, como sempre tem se verificado no desenvolvimento das chamadas políticas públicas, ${ }^{33}$ haveria de ser sanada pela superação da ignorância sobre a eficácia técnica, ou seja, mais ações educativas.

Contudo, esta impossibilidade de tradução entre racionalidade técnica e razoabilidade experiencial foi vivida também pelos pesquisadores e não apenas pelos granjeirences. Houve por parte dos universitários, que lá permaneceram por cerca de um mês, a rejeição à água considerada tecnicamente adequada ao consumo humano pelas mesmas razões apresentadas pelos moradores: sabor, aparência, efeito sobre o corpo, animais nas margens do açude etc. Quando falamos aqui, portanto, de desencontro entre perspectivas, não estamos nos referindo à oposição nós (urbanos, esclarecidos, conhecedores) e eles (interioranos, desinformados, ignorantes). De modo análogo, a complexidade a que nos referimos 
acima não é devida à diferença de inserção social, econômica ou cultural, mas é constituída por engajamentos distintos no mundo particular em questão.

Dito de outra forma, a imersão no fluxo da vida rotineira, a distância e a proximidade com esta vida, o tipo de relação com a água e os conhecimentos sobre ela que estavam em disputa nos pareceram ser centrais à compreensão do desentendimento observado. Um desentendimento que, é relevante destacar, se dava entre pessoas que viviam em Granjeiro (inclusive os recém-chegados, como os pesquisadores) e aqueles que lá iam para desenvolver empreendimentos de política pública. Como se observou nas entrevistas com as autoridades locais, embora discursivamente se distanciassem dos demais moradores (qualificados como ignorantes), elas mantinham práticas semelhantes (como deixar a água "descansar" e elogiar a água dos chafarizes) e sabiam descrevê-las, com frequência, minuciosamente.

Desloquemo-nos, agora, para a polaridade que mapeamos como central ao conflito sobre os usos da água em Granjeiro. Observamos, de um lado, engenheiros da CAGECE e da Funasa, não residentes neste lugar, expondo as suas verdades absolutas sobre as relações entre saneamento (tratamento e abastecimento de água para consumo humano) e saúde (redução das doenças de veiculação hídrica), mas apartadas da experiência com a água especificamente de Granjeiro; de outro, seus moradores afirmando suas verdades sobre a relação entre as qualidades e os usos das diversas águas disponíveis, verdades estas construídas cotidianamente através do uso de suas diferentes águas. Se todo enquadramento dual da realidade é reducionista, tal estratégia visa aqui dar destaque à tensão considerada fundante no universo etnográfico investigado. Desde já assumimos a limitação de suspender a diversidade interna aos polos e às nuanças que os conectam, confiando que os ganhos a superam e a justificam.

Assim, o que nos pareceu estar em jogo no que diz respeito às águas de Granjeiro não era a expressão de lógicas antagônicas ao lidar com esta realidade (lógica sensitiva versus lógica técnica), mas sistemas de relevância cujo maior ou menor distanciamento do manejo cotidiano das águas parecia definir o tipo de verdade acionada (Schutz, 1967, 1979). Viver em Granjeiro e provar, beber as diferentes águas, banhar-se ou cozinhar com elas - com seus sabores, transparências e aparências, profundidades, ambientes e redes de relações diferenciadas - produziriam, esta é nossa aposta interpretativa, antecipações próprias sobre suas qualidades e usos apropriados. Assim, no conhecimento à mão acionado, embora seu horizonte contivesse critérios técnicos, a experiência vivida do sabor desagradável da água tratada, do mal-estar físico por ela propiciado ou da sua maior capacidade de sujar a caixa d'água, por exemplo, revelou-se muito mais 
adequada para o cuidado de si e o bem viver cotidianos do que a informação de que esta água era tecnicamente mais saudável. Uma adequação que, por sua vez, parecia apropriada também para os outsiders que por lá permanecessem tempo suficiente para compartilhar este cotidiano. O desafio interpretativo que se impunha aos investigadores não se resolveria na busca por enquadrá-lo nos termos de sistemas de pensamento distintos e distintivos de coletividades.

Tampouco o recorte deste complexo de significados em termos de visões de mundo ou representações de mundo em conflito surgiu como apropriado, pois, tal qual a ordenação em termos de lógicas antagônicas, estas abordagens privilegiam os esquemas interpretativos (valores, sensações, sentimentos, opiniões etc.) consolidados e não permitem apreender a dinâmica central para a constituição de significados: sua relação com a ação no mundo e o potencial a ser validado ou não a cada experiência. Desta perspectiva, a análise por meio da oposição entre lógicas, visões ou representações do mundo, com sua ênfase sincrônica e atemporal, não se apresentou rentável em um contexto etnográfico que, como o da vivência das águas em Granjeiro, exigia uma abordagem que permitisse apreender o processo da negociação conflituosa em curso no dia a dia.

O aparato conceitual da fenomenologia voltada para a compreensão do mundo social, nos termos propostos por Schutz (1967, 1979), que permite articular a sociologia compreensiva de Max Weber com as fenomenologias de Husserl e Bergson e o pragmatismo de James ${ }^{34}$ possibilitou-nos abordar as práticas sociais em seu poder de constituição de sentidos que se processa no ir e vir entre ações no mundo, percepções do mundo e verificação de conhecimentos sobre o mundo. ${ }^{35}$ No caso específico aqui abordado, a qualidade superior da água do Açude para o consumo, afirmada pelos especialistas (engenheiros e educadores em saúde), não logrou ser confirmada no seu uso cotidiano pelos residentes em Granjeiro, ao provocar mal-estar físico e desconfiança sensorial. Não se tratava, portanto, de crenças, representações, visões ou lógicas cuja razoabilidade não resistiria ao escrutínio científico de suas bases ou que sucumbiria ao bombardeio de informações técnicas, mas sim de um tipo de veracidade que foi estabelecida a partir dos efeitos negativos obtidos no mundo da vida quando a água clorada, oriunda do Açude, foi submetida à experiência.

Este contexto de negociação e conflito em torno de um procedimento novo de manejo técnico-sanitário da água nos possibilitou lembrar ainda que qualquer artefato técnico - em nossa pesquisa um processo de tratamento da água de um determinado manancial - implica uma política tecnológica sujeita à atribuição de significados destoantes e requer tomadas de decisão localizadas em múltiplos mundos hierarquizados, em termos de valores (materiais e simbólicos), e que 
envolvem sujeitos (indivíduos e instituições) em distintas posições de poder. A relevância desta lembrança está em tornar visível a disputa que, uma vez resolvida, tenderia a desaparecer na naturalização própria da vida cotidiana - mas que nesta não se esgotaria, podendo vir a reverberar e a ganhar novas traduções, inclusive nas teorias sociais. ${ }^{36}$

Recebido em 10/08/2011

Aceito em 19/08/2011

Carla Costa Teixeira é professora associada 1 do Depto. de Antropologia da Universidade de Brasília, no qual é coordenadora do Laboratório de Antropologia, Saúde e Saneamento (LASS); é pesquisadora 2 do CNPq e líder do Grupo de Pesquisa Antropologia Política da Saúde, e tem se dedicado principalmente ao estudo dos seguintes temas: etnografia da vida política, políticas públicas de saúde indígena e relações entre saúde e saneamento.

Luís Cláudio de Moura é graduado em História e Ciências Sociais, com mestrado em História das Ideias. Atualmente é doutorando em História Cultural pela Universidade de Brasília. Trabalha com pesquisa na área de Antropologia da Saúde e pensamento latinoamericano. É professor de História e Bioética no Instituto Federal de Goiás - campus Formosa.

Anna Davison é mestre em Antropologia Social pelo Programa de Pós-Graduação em Antropologia Social (PPGAS) da Universidade de Brasília (UnB), instituição onde também atuou como estagiária e bolsista de iniciação científica no Laboratório de Antropologia Saúde e Saneamento (LASS/UnB). Possui experiência nas áreas de Antropologia da Saúde e do Consumo. 


\section{Notas}

1. Pinheiro, M. (1992:106). Na ocasião da implementação oficial de Granjeiro como município, durante as comemorações de 1958, conheceu-se uma "Marcha", de autoria de seu morador e comerciante José Dantas, na qual se cantava esta estrofe de exaltação à cidade.

2. Cícero Romão Batista, o padre Cícero, nasceu no Crato, em 1844, e faleceu em Juazeiro do Norte, em 1934. Conta-se que em 1889, durante uma comunhão, a hóstia por ele consagrada sangrou na boca de uma beata e o povo considerou o fato um milagre. A notícia espalhou-se e Juazeiro passou a ser visitada por peregrinos, interessados nos poderes do padre. O Vaticano, por sua vez, considerou o tal milagre um embuste e suspendeu-o. Posteriormente, padre Cícero ingressou na política e chegou a ser prefeito de Juazeiro. Após sua morte, sua fama e seus feitos foram divulgados entre as camadas populares e, embora ainda banido pela Igreja, tornou-se, de fato, um santo entre os sertanejos. Em 2001, padre Cícero foi eleito o Cearense do Século, em pesquisa organizada pela Rede Globo e a TV Verdes Mares. Até hoje a Igreja não o reabilitou.

3. A questão da falta de água é essencial para a compreensão do valor da água no dia a dia, como também do seu valor como "moeda" para políticas públicas. Adotamos neste artigo o entendimento da seca como um fato social, político, não apenas fruto de condicionantes naturais (vide Andrade, 1986; Ribeiro apud Lima, 2002).

4. Além da sede, foco da análise aqui realizada, o município conta com outros sítios (o município oficialmente não tem distritos) que também surgiram da fixação de famílias vindas de Barbalha ou Crato, em cuja diocese está o município, exceção feita ao Sítio Serrinha (maior que a sede em número de habitantes, mas sem sua centralidade na vida do município). Os moradores deste sítio descendem de famílias de Altos, no Piauí, que foram para o Cariri em busca do padre Cícero, que lhes teria indicado o local para se fixarem.

5. Este fio condutor se revelou profícuo pelo fato de o município ter sido alvo de ações governamentais (numa articulação entre governos federal e estadual) ligadas à infraestrutura de abastecimento de água e que incluíram campanhas "educativas" sobre o uso adequado das águas do Açude do Junco que abasteciam as residências.

6. A pesquisa de campo em Granjeiro foi realizada pelos pesquisadores Anna Davison e Luís Cláudio Rocha Henrique de Moura, sob a coordenação de Carla Costa Teixeira, entre julho e agosto de 2005, tendo sido precedida por uma breve pesquisa exploratória em 2004 efetuada por Anna Davison. A realização do trabalho de campo em 2005 integrou um projeto de pesquisa mais amplo, e contou com o apoio da Fundação Nacional de Saúde por meio de edital público de pesquisa. Para maiores informações sobre a preparação e os resultados desta pesquisa, ver Ministério da Saúde, 2004 e Teixeira et al., 2010.

7. Este foi o caso de um grupo de uns 10 jovens de Caririaçu, cidade próxima, com 
aproximadamente 15.000 habitantes, que haviam ganhado um concurso de quadrinhas e recebeu como prêmio um dia passado à beira do Açude. Nos finais de semana, o Junco recebe algumas visitas de banhistas de outras cidades e moradores. À noite, quando não há festas em outros sítios ou em outras cidades, ocorre um movimento maior em seu principal bar (a Churrascaria), com caixas de som com forró a todo volume.

8. No livro Retalhos do Cariri (Pinheiro, 1992), existe um subcapítulo sobre os mitos do açude. Em nossa pesquisa encontramos alguns. Um destes mitos é sobre um bebê que, ainda pagão, fora jogado pela mãe no açude. Por não ser batizada, essa criança tornouse uma cobra muito grande, como costumava ser enfatizado pelos moradores. Além de grande, esta cobra também era considerada perigosa. De acordo com depoimentos, existiam casos de ataques do réptil às pessoas no Açude. Uma das informantes acabara de fazer recentemente um trabalho para a escola no qual um capítulo era denominado "Mistérios sobre as águas de Junco”.

9. Secretário de Gabinete de Planejamento e Coordenação do município. Entrevista dada em 17 de julho de 2005.

10. Segundo se pôde averiguar, a água custava na ocasião $\mathrm{R} \$ 9,30$ (nove reais e trinta centavos) se o consumo fosse até 10 mil litros.

11. O transporte de dois baldes ou latões, carregados nas pontas de uma madeira sobre os ombros, custava cinquenta centavos (julho/agosto de 2005).

12. Não conseguimos obter junto aos moradores e às autoridades locais informações sobre a capacidade de armazenamento das cisternas. O dimensionamento destas requer a consideração de variáveis, tais como extensão do telhado, índice pluviométrico, número de residentes, hábitos de consumo e custo; podendo variar de 4201 a 12.0001 (Terry s/d, disponível em: http://www.abcmac.org.br/files/simposio/3simp_terrytomas_escolhadecisternas.pdf. Acesso em 02/02/2012).

13. Dona Léa residia na sede do município, ou seja, dispunha de água encanada em sua casa e também gozava da proximidade dos chafarizes. Os nomes reais dos moradores de Granjeiro foram substituídos por nomes fictícios; apenas as personalidades públicas tiveram suas denominações mantidas.

14. Outra questão de fundo econômico levantada foi a duração do sabão que, segundo relatos, poderia durar até 4 vezes menos se fosse utilizado em água encanada. Soubemos que o preço da água iria aumentar na época de 30 centavos para 40 centavos o $\mathrm{m}^{3}$.

15. Para os interessados na discussão antropológica sobre as percepções sensórias na experiência de diferentes formações sociais, ver a coletânea já clássica organizada por Howes (1991) e, para uma apresentação mais atual deste campo de discussão, ver Porcello et al. (2010). No que se refere a um aprofundamento das várias dimensões da água em um contexto particular, consultar Strang (2004).

16. Tal conflito de informações não logrou ser resolvido em campo, pois não 
conseguimos ter acesso a medições da qualidade da água do poço ou a algum técnico que fosse por ela responsável. Conseguimos apenas o resultado da análise da água do açude propiciada pela CAGECE.

17. Poucos dias antes, tivemos a visita de um "agente da SUCAM" que veio inspecionar a casa, especificamente a caixa d'água, onde colocou uma substância preventiva de larvas de mosquito. Depois do trabalho, afirmou que estava tudo bem com a caixa d'água. No dia seguinte, quando fomos cozinhar, aparamos na panela uma "pequena lesminha" junto com a água colhida da torneira.

18. Ouvimos falar também de um método para manter a água da caixa livre de larvas de mosquito, que consistia em colocar ali pequenos peixinhos ("piabinhas") para comerem as larvas depositadas nesse tipo de reservatório.

19. De maneira geral, as pessoas não ferviam a água e era raro ver casas que possuíssem filtro de barro. Um dos motivos prováveis da ausência de filtros era o seu preço que, à época, dependendo do tamanho, custava em torno de R\$40, R\$ 60.

20. O cemitério da sede Granjeiro está localizado na zona central da cidade, pouco acima da igreja, em uma área em um nível muito mais alto do que o nível do açude, provavelmente derramando suas águas de chuva no reservatório. Segundo Retalhos do Cariri (Pinheiro, 1992), o cemitério foi fundado em 1877, quando a "Seca dos Dois Setes" assolou a região, produzindo um elevado número de vítimas. Antes desta data, os mortos de Granjeiro eram levados a pé até as cidades vizinhas, principalmente para os cemitérios de Lavras e Várzea Alegre. Em 1818, houve uma gripe, forte e generalizada, denominada bailarina, que causou grande mortandade entre a população local. Os túmulos mais antigos que encontramos são datados da segunda década do século XX. Hoje, não há mais espaço para novas lápides, é já há uma discussão quanto à construção de um novo cemitério. Para maiores reflexões sobre a poluição por morte em Granjeiro, consultar Davison (2006).

21. A expressão "melhoria sanitária domiciliar" refere-se à construção de banheiros (vaso sanitário e pia) com caixa d'água e esgotamento (fossa séptica) próprios.

22. Uso o termo "educativo" por este ser utilizado no município, mas não concordamos ser ele o melhor termo a ser empregado.

23. Foram realizadas cinco entrevistas com representantes do poder público e cinco grupos de discussão (Fishman, 1977) com habitantes do município. O primeiro grupo ocorreu em 18/07, contando com a participação de três homens adultos e quatro mulheres, além de dois adolescentes que encenaram uma peça. Do segundo, em 28/07, fizeram parte sete moças e um rapaz, todos adolescentes. O terceiro grupo foi realizado na Serrinha, em 30/07, comparecendo quatro homens e três mulheres. O quarto encontro ocorreu no Colégio Gonzaga Mota, no dia 04/08, e teve a presença de três professoras, quatro alunos e duas alunas. Vimos também uma fita de vídeo VHS, na qual tivemos a oportunidade de assistir a um amanhecer em tempos de seca. 
24. Para maiores informações gerais sobre o Projeto Alvorada, consultar http:// bvsms.saude.gov.br/bvs/publicacoes/projeto_alvorada.pdf

25. O tema do saneamento e sua vinculação com políticas públicas possui uma rica bibliografia. Entre alguns trabalhos consultados, destacamos os de Barbosa, 1994; Duarte, 2001; Lima, 2005; Gerschman, 1995; Ribeiro apud Lima, 2002; Hochman, 1998.

26. É notável como o material distribuído e trabalhado com a população infantiliza a percepção do adulto, trazendo figuras pouco explicativas e direcionadas a crianças como, por exemplo, uma cartilha com personagens coloridos no estilo revista em quadrinhos, cuja capa apresenta o título "Pingo e Gota D’água em Esquadrão contra o Desperdício".

27. Tivemos a oportunidade de presenciar uma vaquejada em Várzea Alegre. A festa teve a duração de uma semana e estava bastante cheia.

28. Infelizmente, não tivemos a oportunidade de observar o evento, pois este aconteceria em setembro de 2005. No entanto, soubemos mais tarde que o concurso foi suspenso, devido às disputas políticas em torno da cassação do prefeito.

29. Para uma análise sobre o uso da água e a construção de suas representações como capital político em Granjeiro, vide Moura (2010).

30. Para uma discussão específica sobre a relevância de lavar as mãos para a saúde humana, ver Curtis \& Cairncross (2003); para reflexões mais abrangentes sobre a relação entre saúde e ambiente, consultar, para o Brasil, Minayo \& Miranda (2002) e, para as conexões entre água e saúde em diferentes contextos, ver Whiteford \& Whiteford (2005).

31. Referimo-nos aos engenheiros da Fundação Nacional de Saúde que participaram do comitê de avaliação dos relatórios parcial e final desta pesquisa (financiada através de edital pela Funasa) e a alguns engenheiros com quem tivemos a oportunidade de discutir a pesquisa em Fortaleza, um deles alto funcionário da CAGECE.

32. É importante aqui mencionar que há controvérsias sobre os efeitos da cloração da água para a saúde humana no próprio campo disciplinar da epidemiologia e da engenharia sanitária ou da saúde pública (Meyer, 1994).

33. Sobre o desenvolvimento de uma antropologia das políticas públicas, consultar Shore \& Wright (1997). Para uma discussão desta categoria e seus desdobramentos na antropologia brasileira, ver Souza Lima \& Macedo e Castro (2008), e Teixeira \& Souza Lima (2010).

34. Agradecemos a generosidade de Igor Zeredo de Cerqueira por ter compartilhado conosco suas reflexões sobre as obras de William James e Henri Bergson.

35. Para uma reflexão no âmbito da fenomenologia da técnica mais ancorada na obra de Heidegger, consultar Harman (2010).

36. Inspiramo-nos aqui em Pinch (2010) e sua crítica à abordagem de Latour no que se refere à técnica como um processo de delegação aos não humanos de uma forma de moralidade formalmente exercida por humanos, pois esta abordagem desconsideraria o processo de deliberação entre humanos que se encontra na origem da técnica. 


\section{Referências bibliográficas}

ANDRADE, Manuel Correia de. 1986. "A invenção do estado e a seca no nordeste do Brasil". Revista de Economia Política, v. 6, n. 4, out.-dez.

BARBOSA, José Policarpo de Araújo. 1994. História da saúde pública do Ceará: da Colônia a Vargas. Fortaleza: Edições UFC.

CURTIS, Valerie \& CAIRNCROSS, Sandy. 2003. "Effect of washing hands with soap on diarrhoea risk in the community: a systematic review". Lancet Infectious Diseases, 3(5):275-281.

DAVISON, Anna. 2006. "Morte como fator poluidor: o caso de Granjeiro, CE". Monografia de graduação, Departamento de Antropologia, Universidade de Brasília.

DUARTE, Renato. 2001. "Seca, pobreza e políticas públicas no nordeste do Brasil". In: Alicia Ziccardi. Pobreza, desigualdad social y ciudadanía. Los límites de las políticas sociales en América Latina. CLACSO, Consejo Latinoamericano de Ciencias Sociales, Ciudad Autónoma de Buenos Aires, Argentina. Disponível em: http://bibliotecavirtual.clacso. org.ar/ar/libros/pobreza/duarte.pdf. Acesso em: 10/07/2009.

GERSCHMAN, Sílvia. 1995. A Democracia Inconclusa: Um Estudo da Reforma Sanitária Brasileira. Rio de Janeiro: Fiocruz.

HARMAN, Graham. 2010. “Thecnology, objects and things in Heidegger”. Cambridge Journal of Economics, 34:17-25.

HOCHMAN, Gilberto. 1998. A era do saneamento. São Paulo: Hucitec.

HOWES, David. 1991. The varieties of sensory experience. A sourcebook in the anthropology of the senses. Toronto: University of Toronto Press.

LIMA, Nísia T. et al. 2005. Saúde e Democracia: história e perspectiva do SUS. Rio de Janeiro: Editora Fiocruz.

MEYER, Sheila T. 1994. "O uso de cloro na desinfecção de águas, a formação de trihalometanos e os riscos potenciais à saúde pública”. Cadernos de Saúde Pública, Rio de Janeiro, 10(1):99-110, jan./mar..

MINAYO, Cecília de S. \& MIRANDA, Ary C. (orgs.). 2002. Saúde e ambiente sustentável: estreitando nós. Rio de Janeiro: Editora Fiocruz..

MINISTÉRIO DA SAÚDE. Avaliações de impacto na saúde das ações de saneamento: marco conceitual e estratégia metodológica. Organização Pan-Americana da Saúde. Brasília: Ministério da Saúde. 
MOURA, Luís Cláudio Rocha H. 2010. “Entrando água na política: saneamento, representações e poder em uma pequena comunidade do Cariri”. Monografia de graduação, Departamento de Antropologia, Universidade de Brasília.

PINHEIRO, Maria Evânia C. de Brito. 1992. Retalhos do Cariri: Granjeiro 1910-1992. Fortaleza: Multigraf Editora.

PINTCH, Trevor. 2010. "On making infrastructure visible: putting the non-humans to rights". Cambridge Journal of Economics, 34:77-89.

PORCELLO, Thomas et al. 2010. "The reorganization of the sensory world”. Annual Review of Anthropology, 39:51-66.

RIBEIRO, Rafael Winter. 2002. "A construção da seca como problema: administração pública e representações da natureza durante a seca de 1877/1879 no Ceará”. In: Antônio Carlos de Souza Lima (org.). Gestar e gerir: estudos para uma antropologia da administração pública no Brasil. Rio de Janeiro: Relume Dumará. Núcleo de Antropologia da Política/ UFRJ.

SCHUTZ, Alfred. 1967. The phenomenology of the social world. Evanston: Northwestern University Press.

1979. Fenomenologia e relações sociais. Rio de Janeiro: Jorge Zahar Editores.

SHORE, Cris \& WRIGHT, Susan (orgs.). 1997. Anthropology of Policy. Critical perspectives on governance and power. London: Routledge.

SOUZA LIMA, Antonio Carlos de \& MACEDO E CASTRO, João Paulo. 2008. "Política(s) Pública(s)”. In: Osmundo Pinho \& Livio Sansone (orgs.). Raça: novas perspectivas antropológicas. Salvador: Associação Brasileira de Antropologia/ Editora da Universidade da Bahia.

STRANG, Veronica. 2004. The meaning of water. Oxford: Berg.

TEIXEIRA, Carla C. \& SOUZA LIMA, Antonio Carlos de. 2010. "A Antropologia da Administração e da Governança no Brasil: área temática ou ponto de dispersão?”. In: Carlos B. Martins \& Luiz Fernando D. Duarte (orgs.). Horizontes das Ciências Sociais no Brasil. Antropologia. São Paulo: Instituto Ciência Hoje/ Editora Barcarolla/ Discurso Editorial.

TEIXEIRA, Carla C. et al. 2010. "Percepções e Usos da Água em Pequenas Comunidades: Uma Perspectiva Antropológica”. $5^{\circ}$ Caderno de pesquisa em engenharia de saúde pública / Fundação Nacional de Saúde. Brasília: Fundação Nacional de Saúde.

WHITEFORD, Linda \& Whiteford, Scott (eds.). 2005. Globalization, water, and health: resource management in times of scarcity. Santa Fé: School of American Research Press. 


\section{Resumo}

Este artigo apresenta uma análise dos usos e das percepções da água em Granjeiro (CE), localidade que conta com uma interessante pluralidade de ofertas de águas. Tal pluralidade permitiu que os granjeirences formulassem estratégias diversificadas para a sua utilização, dependendo da fonte, da localidade no município e da estação do ano, ou ainda das experiências sensoriais advindas do manejo das águas e que levavam à atribuição de adjetivos para cada tipo de água e findaram por determinar seus usos. Estas variáveis sensoriais, no entanto, não são reconhecidas pelo serviço técnico de saneamento do estado, o que gerou desentendimentos. Para dar conta do descompasso entre moradores e responsáveis técnicos pelas águas, este artigo lança mão de uma perspectiva fenomenológica que permite perceber como a proximidade com o manejo cotidiano das águas ou o distanciamento dele define o tipo de verdade acionada pelos diferentes atores, já que torna possível compreender as práticas sociais em seu poder de constituição de sentidos, que se processa no ir e vir entre ações no mundo, percepções do mundo e verificação de conhecimentos sobre o mundo. Viver em Granjeiro e lidar com as diferentes águas produziram, esta é a nossa aposta interpretativa, antecipações próprias sobre suas qualidades e usos apropriados.

Palavras-chave: hierarquia das águas, experiência sensória, fenomenologia, política pública, Brasil

\section{Abstract}

This paper analyses the uses and perceptions of water in Granjeiro, Ceará, a city marked by an interesting plurality regarding water supplies. Such plurality allowed the people from Granjeiro to develop diversified strategies to use water according to its source, locality, the season of the year and even the sensorial experiences resulting from its usage, which have led to the attribution of adjectives to each type of water and eventually determined its uses. Those sensorial variables, however, are not recognized by the State's sanitation technical service, resulting in misunderstandings. In order to bridge the gap between dwellers and technicians responsible for the water, this paper makes use of a phenomenological perspective that allows the understanding of how the proximity with the daily use of waters or the detachment from that use defines the kind of truth recalled by different actors, since the use of water will make it possible to understand the social practices and their ability to constitute meanings that are processed in the to-and-fro between actions in the world, perceptions of the world and the verification of knowledge regarding the world. Living in Granjeiro and dealing with its different waters - according to our interpretative bid - produced particular assumptions regarding its qualities and adequate uses.

Keywords: water hierarchy, sensory experience, phenomenology, public policy, Brazil 